\title{
Fumaria parviflora improves liver damage and lipid profile changes in STZ-induced diabetic rats
}

\author{
Fateme Kooshki ${ }^{1,2,3}$, Hamid Reza Niazkar ${ }^{4}$, Shabnam Shirazi ${ }^{1,2}$, Vahid Asghari Azar ${ }^{5}$, Maryam \\ Moghimian $^{6}$, Arash Karimi ${ }^{1,2,3 *}$ iD \\ 1. Student Research Committee, Tabriz University of Medical Sciences, Tabriz, Iran \\ 2. Nutrition Research Center, Faculty of Nutrition and Food Sciences, Tabriz University of Medical Sciences, Tabriz, Iran \\ 3. Department of Clinical Nutrition, Faculty of Nutrition and Food Science, Tabriz University of Medical Sciences, Tabriz, Iran \\ 4. Student Research Committee, Gonabad University of Medical Sciences, Gonabad, Iran \\ 5. Department of Medical Genetics, Faculty of Medicine, Tabriz University of Medical Sciences, Tabriz, Iran \\ 6. Department of Physiology, School of Medicine, Gonabad University of Medical Sciences, Gonabad, Iran
}

\begin{abstract}
Introduction: Chemical drugs and herbal medicine play a significant role in the management of diabetes mellitus complications. The aim of this study was to investigate the effects of Fumaria parviflora as an herbal source and glibenclamide as a chemical drug, on the liver tissue of diabetic rats.

Methods: Male Wistar rats $(n=32)$ were classified randomly into four groups (8/group), including control, diabetic (induced by $50 \mathrm{mg} / \mathrm{kg}$ streptozocin), $250 \mathrm{mg} / \mathrm{kg}$ hydroalcoholic extract of Fumaria parviflora (DFP) and $5 \mathrm{mg} / \mathrm{kg}$ glibenclamide groups. After 21 days of treatment, liver tissues and blood samples were stored at $-80^{\circ} \mathrm{C}$ to test lipid profile, liver enzymes and some oxidative stress markers.
\end{abstract}

Results: In the diabetic group compared to the control group, the activities of SOD and GPx and also the serum levels of alkaline phosphatase were significantly decreased, while the levels of malondialdehyde, alanine aminotransferase and aspartate transaminase enhanced. Treatment with DFP and glibenclamide could manage the levels of all mentioned-parameters. Furthermore, in both treated groups, the rate of damages in the liver of rats reduced compared to the diabetic group.

Conclusion: According to the obtained results, the administration of DFP or glibenclamide could ameliorate the deleterious effects of diabetes mellitus on some investigated-parameters. As there were no difference between DFP and glibenclamide effects, Fumaria parviflora could be considered as an alternative drug, at least for the diabetic complications examined in this study. However, further investigation is needed.

http://dx.doi.org/10.32598/ppj.24.3.80

\section{Keywords:}

Fumaria parviflora;

Glibenclamide;

Diabetes mellitus;

Liver;

Oxidative stress

\section{* Corresponding author:}

\section{A. Karimi}

Email:

karimi.a@tbzmed.ac.ir

Tel: +98 (903) 4510010

Received 6 June 2019;

Received in revised form 5 June 2020; Accepted 8 June 2020

\section{Introduction}

Diabetes Mellitus (DM) is one of the most important diseases among metabolic disorders (American diabetic association, 2017). Both types of diabetes (type 1 and type 2) are caused by the lack of insulin production, insulin resistance and the gradual 
degradation of pancreatic $\beta$-cells (American diabetic association, 2017). It is estimated that the number of people with DM will increase to 439 million adults by 2030 (Koye et al., 2018). Insufficient insulin and hyperglycemia, which is resulted from a lack of insulin, could disrupt carbohydrate, lipid and protein metabolism (American diabetic association, 2017; Abtahi-Eivari et al., 2020), leading to damage of various organs including cardiovascular system, reproduction system, liver, kidneys and eyes (Almalki and Alghamdi, 2019; Rawshani et al., 2017; Sauder et al., 2019; Shoorei et al., 2019).

In diabetic patients, dyslipidemia with a prevalence of $72-85 \%$, is appeared due to insulin deficiency and insulin resistance (American diabetic association, 2017). Also, hyperglycemia is led to several abnormalities in lipid metabolisms such as hypertriglyceridemia, elevated-levels of very-lowdensity lipoprotein (VLDL), LDL, chylomicron and decreased-level of high-density lipoprotein (HDL) (American diabetic association, 2017). On the other hand, hyperglycemia could increase the accumulation of free fatty acids in the liver and stimulate the production of hepatic triglyceride via regulating lipogenesis and reducing oxidation of free fatty acids, which is resulted in lipotoxicity and steatosis (American diabetic association, 2017; Chaudhury and Aggarwal, 2018).

It has been reported that following DM in serum, levels of alanine aminotransferase (ALT) and $Y$ glutamyltransferase (GGT) which mainly produce in the liver, are increased (Fraser et al., 2009). Interestingly, the higher serum concentration of GGT is considered as a useful marker for the development of DM and oxidative stress (Lee et al., 2004). Nowadays, physicians are using chemical antidiabetic drugs, including glibenclamide, sulfonylurea, thiazolidinediones and $\alpha$-glucosidase, to control blood glucose and inhibition of diabetes complications (Gamble et al., 2018; Srinivasan et al., 2018). However, using of mentioned-drugs could be associated with serious side-effects (Chidambara et al., 2018).

Medicinal plants that are currently using to the management of blood glucose, work via various mechanisms such as decreasing insulin resistance and levels of oxidative stress, caused by free radicals in the pancreas tissue (Abtahi-Evari et al., 2017). Fumaria parviflora $\mathrm{L}$, which is belonged to the
Papaveraceae family, is an herb annually grows in vast areas of Pakistan, Iran, Indian and Turkey (AlSnafi, 2018; Shokoohi et al., 2018). Traditionally, it has been used to the treatment of several diseases related to skin, liver and bile duct (Al-Snafi, 2018). High-performance liquid chromatography analysis showing that Fumaria parviflora is contained various amounts of compounds including fumaritine, paprafumicin, paprarine, fumaranine, coptisine, adlumidiceine, parfumine and etc (Al-Snafi, 2018; Kumar et al., 2009; Tripathi et al., 2010). Therefore, it has a wide range of pharmacological properties including antioxidant and anti-inflammatory activities (Al-Snafi, 2018).

A high dose of Fumaria parviflora had protective effects on hepatocytes against liver injury induced by carbon tetrachloride, and also could reduce liver enzymes such as ALP, serum glutamic oxaloacetic transaminase and serum glutamic pyruvic transaminase (Alqasoumi et al., 2009). Administration of methanolic extract of Fumaria parviflora decreased the level of blood glucose in diabetic rats (Fathiazad et al., 2013). Treatment with Fumaria parviflora could also reduce the levels of malondialdehyde (MDA), TNF- $\alpha$, IL-6 and IL-1 in rats, in which inflammation was induced by aspirin (Rizvi et al., 2017). Although in traditional Iranian medicine Fumaria parviflora had been used as a source for the treatment of liver and bile ducts disorders, recent studies reported that it could affect the lipid profile (decrease the levels of LDL, triglycerides [TG] and cholesterol and increase HDL level), blood glucose and liver enzymes in diabetic patients (Al-Snafi, 2018; Osadebe et al., 2014). Because few studies have been done on the anti-diabetic effects of Fumaria parviflora, the purpose of this study was to investigate the effect of Fumaria parviflora (a traditional herbal medicine) on liver tissue and biochemical factors in diabetic rats; also the glibenclamide (a chemical drug) was used as control.

\section{Materials and methods}

\section{Plant material}

Fumaria parviflora leaves were collected from Fars Province, Kazeroun City, by a botanist in July 2017. The identity of this plant was approved at the Central Herbarium of Tehran University. To provide the whole extract of Fumaria parviflora leaves, $1 \mathrm{~kg}$ of leaves was dried at $25^{\circ} \mathrm{C}$. After grinding for extraction from 
the dried plants, obtained powder was dissolved in 2 liters of ethanol (96\%) and then kept at room temperature for $48 \mathrm{~h}$ (Shokoohi et al., 2018). The solution was filtered over this period after regularly shaking. Then, it was centrifuged for $5 \mathrm{~min}$ at $1008 \mathrm{~g}$. At the final procedure, the solution was poured into an open-top container and the solvent was dry out (Shokoohi et al., 2018). However, $200 \mathrm{~g}$ of a semisolid extract was achieved from $1 \mathrm{~kg}$ of leaves. Finally, the extract was dissolved in normal saline for preparing the appropriate concentration.

\section{Animals}

This experimental study was accomplished on male adult Wistar rats $(n=32,200-250 \mathrm{~g})$. Rats were kept in a place with $25 \pm 2^{\circ} \mathrm{C}$ temperature and $60-70 \%$ humidity on a $12 \mathrm{~h}$ photo-cycle with free access to food and water. The ethical considerations of this study were carried out based on the approved guidelines of laboratory animals of the Research and Technology Deputy of Tabriz University of Medical Sciences (IR.TBZMED.VCR.REC.1397.167).

\section{Diabetes induction}

Induction of diabetes was carried out by intraperitoneal (IP) injection of $50 \mathrm{mg} / \mathrm{kg}$ streptozotocin (STZ) (Sigma-Aldrich, Germany) in a citrate buffer solution with $5 \mathrm{mM}$ volume $(\mathrm{pH}=4.5)$ (Shoorei et al., 2019; Shoorei et al., 2020). The rats with increased blood glucose levels higher than $250 \mathrm{mg} / \mathrm{dl}$ after $72 \mathrm{~h}$ of injection were confirmed to be diabetic (Shoorei et al., 2019).

\section{Experimental design}

Rats were randomly classified into four groups ( $n=8 /$ group) as follows: Group1, rats did not receive any intervention (control group); Group2, diabetic rats received normal saline (DC group); Group3, diabetic group daily treated with hydroalcoholic extract of Fumaria parviflora (250mg/kg, IP) for 21 days (DFP) (Shokoohi et al., 2018); Group4: diabetic group daily treated with glibenclamide $(5 \mathrm{mg} / \mathrm{kg}, \mathrm{IP})$ for 21 days (DG) (Abtahi-Evari et al., 2017).

\section{Biochemical assays}

The examination of serum levels of TG, cholesterol, HDL and LDL was measured by commercial kits (Parsazmun, Iran). The unit of $\mathrm{mg} / \mathrm{dl}$ was chosen for the report of values.

\section{Liver enzyme biochemical assays}

The levels of liver enzymes, alanine transaminase $(\mathrm{ALT})$, alkaline phosphatase (ALP) and aspartate aminotransferase (AST) were measured using commercial kits (Parsazmun, Iran) (Kiafar et al., 2018).

\section{Measurement of the oxidative stress markers}

MDA level was assessed for investigation the lipid peroxidation in the liver. In order to provide a solution of "TBA-TCA-HCL", 375mg of thiobarbituric acid (TBA) was solved in $2 \mathrm{ml}$ of $\mathrm{HCL}$, next added into $100 \mathrm{ml}$ of 15 percent trichloroacetic acid (TCA) (Delkhosh et al., 2019; Shokoohi et al., 2019). A water bath $\left(50^{\circ} \mathrm{C}\right)$ was used for dissolving the sediment, therefore the solution of potassium chloride (5.1\%) used to immediately obtain a homogenized mixture (10\%). Then, $1 \mathrm{ml}$ of the homogenized tissue was blended with $2 \mathrm{ml}$ of TBA-TCA-HCl solution and warmed in boiling water for 45min (Shokoohi et al., 2020). After being cold, it was centrifuged at 1000rpm for 10min. Spectrophotometer (Biospect) was used to read the absorption at $532 \mathrm{~nm}$. Besides, the levels of superoxide dismutase (SOD) and glutathione peroxidase (GPx) were measured according to the methods developed by Sun et al. (1988) and Paglia and Valentine (1967), respectively, using the commercial kits (Ransod and Ransel, Randox Com, UK).

\section{Histopathological investigation}

The liver samples were fixed in $10 \%$ formalin for 4 weeks and the fixative solution was weekly replaced with the refresh solution. After fixation, samples dehydrated and embedded in paraffin to $5 \mu \mathrm{m}$ cutting by a microtome. Finally, all of the samples stained with hematoxylin-eosin. For histopathological analysis, some slides were used to assess the histological changes and other slides were used to evaluate the edema, rupture, hemorrhage in central veins, dilatation in sinusoids and pyknotic nuclei.

\section{Statistical analysis}

All of the obtained values were analyzed by the SPSS software version 18 (SPSS Inc., Chicago, IL, USA). The Kolmogorov-Smirnov test was applied to examine whether the obtained data were normality distributed. The differences between the experimental groups were analyzed by one-way analysis of 
Table 1: Effects of Fumaria parviflora and glibenclamide on lipid profile in diabetic rats

\begin{tabular}{lllll}
\hline Groups & $\begin{array}{l}\text { Cholesterol } \\
\text { (Mean } \pm \text { SD) }\end{array}$ & $\begin{array}{l}\text { HDL } \\
(\text { Mean } \pm \text { SD) }\end{array}$ & $\begin{array}{l}\text { LDL } \\
\text { (Mean } \pm \text { SD) }\end{array}$ & $\begin{array}{l}\text { TG } \\
\text { (Mean } \pm \text { SD) }\end{array}$ \\
\hline Control & $53.71 \pm 8.92$ & $43.54 \pm 5.27$ & $24.14 \pm 2.32$ & $33.21 \pm 3.73$ \\
DC & $84.57 \pm 11.13^{*}$ & $21.92 \pm 2.43^{*}$ & $41.27 \pm 4.53^{*}$ & $70.05 \pm 6.48^{*}$ \\
DFP & $66.42 \pm 9.01^{*}+$ & $35.24 \pm 4.67^{* \dagger}$ & $30.12 \pm 3.07^{* \dagger}$ & $45.57 \pm 4.18^{* \dagger}$ \\
DG & $71.19 \pm 10.07^{* \dagger}$ & $31.32 \pm 5.14^{* \dagger}$ & $32.25 \pm 2.98^{* \dagger}$ & $50.28 \pm 4.96^{* \dagger}$ \\
\hline
\end{tabular}

Control: the control group received normal saline; DC: the diabetic control group received normal saline; DG: the diabetic control group received glibenclamide $(5 \mathrm{mg} / \mathrm{kg})$; DFP: the diabetic group received a hydroalcoholic extract of Fumaria parviflora $(250 \mathrm{mg} / \mathrm{kg})$. SD: Standard deviation. " $P \leq 0.03$ shows a significant difference compared to the control group. ${ }^{\dagger} P<0.05$ shows a significant difference compared to the $\mathrm{DC}$ group.

Table 2: Effects of Fumaria parviflora and glibenclamide on antioxidant properties in diabetic rats

\begin{tabular}{llll}
\hline Groups & $\begin{array}{l}\text { SOD }(\mathrm{U} / \mathrm{ml}) \\
\text { (Mean } \pm \text { SD) }\end{array}$ & $\begin{array}{l}\text { GPx (U/ml) } \\
\text { (Mean } \pm \text { SD) }\end{array}$ & $\begin{array}{l}\text { MDA (nM) } \\
\text { (Mean } \pm \text { SD) }\end{array}$ \\
\hline Control & $3.24 \pm 0.42$ & $24.62 \pm 3.39$ & $11.38 \pm 1.07$ \\
DC & $1.02 \pm 0.34^{*}$ & $8.08 \pm 1.01^{*}$ & $27.07 \pm 3.12^{*}$ \\
DFP & $1.87 \pm 0.11^{* \dagger}$ & $19.82 \pm 2.76^{* \dagger}$ & $18.01 \pm 2.81^{* \dagger}$ \\
DG & $1.58 \pm 0.12^{*}+$ & $15.03 \pm 2.91^{*}+$ & $20.77 \pm 2.05^{* \dagger}$ \\
\hline
\end{tabular}

Control: the control group received normal saline; DC: the diabetic control group received normal saline; DG: the diabetic control group received glibenclamide $(5 \mathrm{mg} / \mathrm{kg})$; DFP: the diabetic group received a hydroalcoholic extract of Fumaria parviflora $(250 \mathrm{mg} / \mathrm{kg})$. SD: Standard deviation. " $P \leq 0.02$ shows a significant difference compared to the control group. ${ }^{\dagger} P<0.05$ shows a significant difference compared to the DC group.

variance (ANOVA), followed by Tukey's post hoc test. The values are expressed as the mean $\pm S D$ and the level of statistical significance was set at $P<0.05$.

\section{Results}

The effects of Fumaria parviflora and glibenclamide on blood parameters, including HDL, LDL, cholesterol and TG

Table 1 shows the amount of the earlier-mentioned parameters. According to Table 1 , in the diabetic group compared to the control group, the serum level of $\mathrm{HDL}$ was significantly decreased $(P<0.03)$, while the levels of LDL, cholesterol and TG increased $(P \leq 0.03)$. In both treated groups (DG and DFP) compared to the diabetic group, the serum HDL level improved $(P<0.05)$, while serum levels of LDL, cholesterol and TG decreased $(P<0.05)$. In this regard, there was no significant difference for all mentioned parameters between two treated groups $(P>0.05)$.
The effects of Fumaria parviflora and glibenclamide on status of antioxidant enzymes

DM led to a significant increase in the amount of MDA and a significant decrease in the activities of SOD and GPx ( $P \leq 0.02$, Table 2). Treatment with Fumaria parviflora and glibenclamide significantly decreased the level of MDA and increased the activities of SOD and GPx $(P<0.05)$. There was no significant difference for all mentioned parameters between two treated groups ( $P>0.05$, Table 2$)$.

\section{The effects of Fumaria parviflora extract and glibenclamide on serum level of AST, ALT and ALP}

These results are presented in Table 3 . In the DC group, the levels of ALT and AST were higher than the DG and DFP groups $(P<0.03)$, while, the level of ALP decreased $(P<0.02)$. In both treated groups (DG and DFP), the amount of ALT and AST significantly decreased compared to the DC group $(P<0.04)$ and also the level of ALP increased $(P \leq 0.04)$. There was 
Table 3: Effects of Fumaria parviflora and glibenclamide on serum levels of AST, ALP, and ALT in diabetic rats

\begin{tabular}{llll}
\hline Groups & $\begin{array}{l}\text { ALP } \\
\text { (Mean } \pm \text { SD) }\end{array}$ & $\begin{array}{l}\text { ALT } \\
\text { (Mean } \pm \text { SD) }\end{array}$ & $\begin{array}{l}\text { AST } \\
\text { (Mean } \pm \text { SD) }\end{array}$ \\
\hline Control & $247.32 \pm 35.21$ & $71.08 \pm 9.25$ & $221.02 \pm 21.27$ \\
DC & $89.49 \pm 13.27^{*}$ & $167.01 \pm 23.62^{*}$ & $332.24 \pm 25.63^{*}$ \\
DFP & $187.75 \pm 20.32^{*}+$ & $127.87 \pm 14.52^{*}{ }^{*}$ & $258.89 \pm 24.0{ }^{*}{ }^{*}$ \\
DG & $176.02 \pm 21.24^{*}+$ & $134.12 \pm 13.58^{*}+$ & $262.39 \pm 22.61^{*}$ \\
\hline
\end{tabular}

Control: the control group received normal saline; DC: the diabetic control group received normal saline; DG: the diabetic control group received glibenclamide $(5 \mathrm{mg} / \mathrm{kg})$; DFP: the diabetic group received a hydroalcoholic extract of Fumaria parviflora $(250 \mathrm{mg} / \mathrm{kg})$. SD: Standard deviation. " $P<0.03$ shows a significant difference compared to the control group. ${ }^{\dagger} P \leq 0.04$ shows a significant difference compared to the DC group.
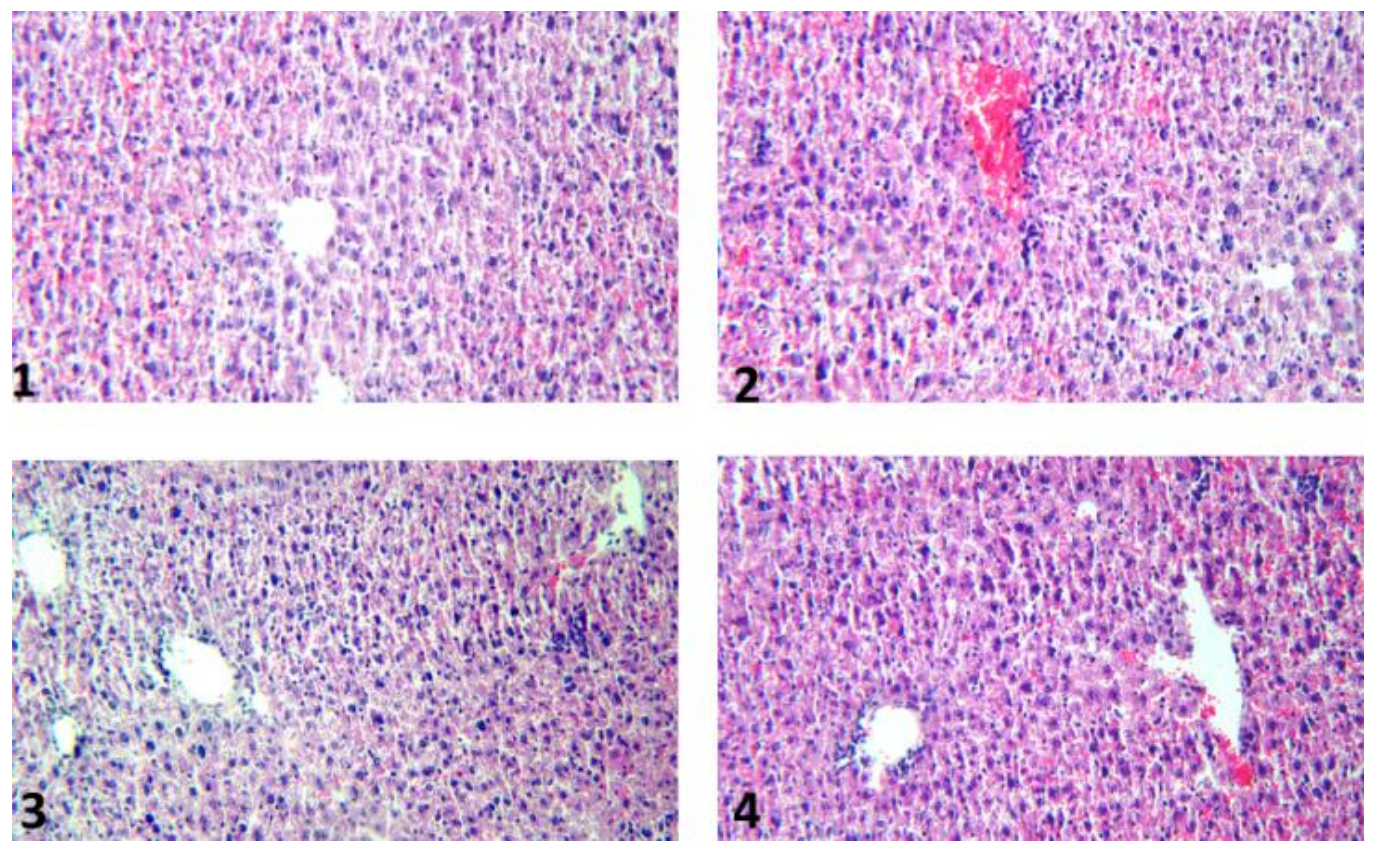

Fig.1. Representative picture of liver histology stained with hematoxylin and eosin (H\&E) in different groups of the study. 1: the control group received normal saline, in this group standard liver architecture is evident; 2: the diabetic control group received normal saline, in this group severe liver damage is apparent; 3: the diabetic group received a hydroalcoholic extract of Fumaria parviflora $(250 \mathrm{mg} / \mathrm{kg}$ ), in this group there was an improvement in the liver structure; 4: the diabetic control group received glibenclamide $(5 \mathrm{mg} / \mathrm{kg})$, in this group, there was an improvement in the liver structure.

no significant difference for all mentioned parameters between two treated groups ( $P>0.05$, Table 3$)$.

\section{Histopathology of livers}

The livers in the control group had a normal histological appearance. DM led to degenerative changes such as edema, rupture, hemorrhage in central veins, dilatation in sinusoids and pyknotic nuclei. In the therapeutic groups, degenerative changes decreased in the liver tissue (Fig. 1).

\section{Discussion}

Although the primary targets in the treatment of DM are insulin and hypoglycemic agents, finding an ideal effective agent with minimum side-effects has still not been achieved (Hasanpour et al., 2018). Chemical drugs in long-term use have limited efficacy and also various side-effects, including increased fat storage, hypoglycemic shock and wasting the fat tissue at the site of the injection, are predictable (Hasanpour et al., 2018). Nowadays, medicinal plants with antioxidative 
properties are widely used for the treatment of different diseases because of their fewer side-effects (Shakya, 2016; Van Wyk and Wink, 2018). Interestingly, the use of medicinal plants is recommended by the World Health Organization (Van Wyk and Wink, 2018).

Fumaria parviflora which is known as wax dolls or fine leaf fumitory in English, has antioxidative, antinociceptive and hepatoprotective effects (Ivanov et al., 2014). Also, the protective effects of Fumaria parviflora extract against paracetamol-induced hepatotoxicity have been proven (Alqasoumi et al., 2009). STZ and alloxan as the two most common substances for inducing diabetes in laboratory animals could lead to damage to pancreatic $\beta$-cells through increasing oxidative stress (Lenzen, 2008) resulting in improper alterations in the serum levels of lipids and lipoproteins (Lenzen, 2008). However, in the diabetic condition, it has been reported that the liver plays an important role in releasing free fatty acids and could increase the cholesterol synthesis and phospholipids and secretion of some lipoproteins to the blood (Guzzaloni et al., 2000).

However, increased blood sugar in STZ-induced diabetic rats could indirectly increase cholesterol, TG and LDL levels, and also decrease the level of HDL (Almeida et al., 2012). Our study showed that intraperitoneal injections of STZ $(50 \mathrm{mg} / \mathrm{kg})$ could induce hyperglycemia and reduce the serum level of insulin during $72 \mathrm{~h}$. Also in our study, the serum HDL level was increased in the DFP group, which was treated with Fumaria parviflora, while the serum LDL, TG and cholesterol levels were decreased. Inconsistent with our results, one study showed that long-term consumption of Fumaria parviflora improved serum levels of cholesterol and TG ( Tajik et al., 2011). In another study, treatment with Fumaria parviflora increased the levels of HDL and cholesterol, while the levels of factors such as cholesterol and TG, which are the main causes of cardiovascular damage, decreased (Roghani, 2014). They conducted that the positive effects of Fumaria parviflora probably is due to the high amounts of antioxidants like flavonoids (Roghani, 2014).

Phytochemical experiments on Fumaria parviflora have shown that this plant is rich in phenolic and alkaloids compounds, which have been reported that these compounds have antioxidant activities because they could reduce several mediators of inflammation such as IL-1, IL-6, TNF- $\alpha$, nitric oxide and prostaglandins (Rizvi et al., 2017). Also, flavonoids, as one of the main components in Fumaria parviflora, are involved in preventing the production of prostaglandins in inflammatory reactions (Rizvi et al., 2017).

In the current study, investigating the levels of oxidative stress factors in the serum of diabetic rats indicated that the level of MDA increased, while the levels of GPx and SOD considerably reduced. MDA is an important product of polyunsaturated fatty acid oxidation and is one of the main factors of oxidative injury to membrane lipids (Maritim et al., 2003; Seghinsara et al., 2019). However, treatment with Fumaria parviflora reduced the level of MDA and enhanced the levels of GPx and SOD, which could possibly be due to the reduced oxidative stress in tissues and the elevated intracellular antioxidant enzyme activities. Therefore, it seems that Fumaria parviflora could reinforcement the antioxidant defense system and reduce oxidative stress. Our histological studies showed that DM led to degenerative changes such as edema, rupture, hemorrhage in central veins, dilatation in sinusoids and pyknotic nuclei. In the therapeutic groups (DFP and DG), degenerative changes were decreased in the liver tissue.

Our results showed that the plasma levels of AST and ALT were enhanced in the diabetic group because of the liver damage caused by DM. The levels of two mentioned-enzymes are increased in the diabetic condition and it has been reported that they are directly involved in the conversion of amino acids to keto acids (Kaleem et al., 2008). Studies showed that levels of two mentioned-enzymes (AST and $A L T)$ are increased in the liver of diabetic animals (Kaleem et al., 2008; Rauter et al., 2010). In our study, treatment with Fumaria parviflora or glibenclamide could decrease the serum levels of AST and ALT. The elevated protein catabolism, urea formation and gluconeogenesis, which are observed in the diabetic condition, might be caused by the development of transaminases (Hatting et al., 2018). It has been also reported that the elevated level of ALT may be due to the hepatocellular injury caused by oxidative stress (Pradeep et al., 2007). Treatment with Fumaria parviflora could modify the levels of mentioned-parameters (Alqasoumi et al., 2009). Therefore, treatment with Fumaria parviflora may be involved in the inhibition of gluconeogenesis and 
hepatocellular damage. However, we strongly suggest that further studies should be carried out to light out how Fumaria parviflora could affect the signaling pathways involved in gluconeogenesis.

Furthermore, the serum level of ALP was higher in the diabetic group than the other groups. This issue may be due to the abundance of free radicals which results in the generation of lipid hydroperoxide and cellular injury. By an injury to the hepatocytes, the leakage of transaminases, bilirubin and ALP is initiated. However, the use of Fumaria parviflora is quite safe at the applied doses and no signs of toxicity or adverse effects were reported in the treated animals (Alqasoumi et al., 2009; Rizvi et al., 2017).

\section{Conclusion}

The obtained results of the current study showed that treatment with Fumaria parviflora extract and glibenclamide could decrease the levels of cholesterol, LDL and TG in diabetic rats and could balance the antioxidant enzyme status. However, no significant difference was observed for all parameters investigated in the present study between two treated groups, glibenclamide and Fumaria parviflora. We suggest other doses of glibenclamide and Fumaria parviflora should be further studied and also a combination of two supplements may light out how they work together against diabetes mellitus. For further studies, it is recommended that the effective ingredients of Fumaria parviflora extract be identified and determine the role of ingredients in regulating the expression level of apoptotic genes and different signaling pathways. It is also recommended that the MicroRNA involved in the process of apoptosis, which has been reduced by the Fumaria parviflora, as well as the expression of genes related to oxidative (such as nuclear factor erythroid 2-related factor-2) and inflammatory pathways (such as nuclear factor kappa $\mathrm{B})$, be performed and finally conducting clinical trials studies.

\section{Acknowledgments}

This study was received a specific grant from Student Research Committee, Tabriz University of Medical Sciences, Tabriz, Iran.

\section{Conflict of interest}

None.

\section{References}

Abtahi-Eivari SH, Shokoohi M, Ghorbani M, Kalarestaghi H, Shoorei H, Bahrami J, et al. Effects of hydroalcoholic extracts of cloves (Syzygium aromaticum) on serum biomarkers, antioxidant status and histopathological changes of kidneys in diabetic rats. Crescent $\mathrm{J}$ Med Biol Sci 2020; 7.

Abtahi-Evari SH, Shokoohi M, Abbasi A, Rajabzade A, Shoorei H, Kalarestaghi H. Protective effect of Galega officinalis extract on streptozotocin-induced kidney damage and biochemical factor in diabetic rats. Crescent J Med Biol Sci 2017; 4: 108-14.

Al-Snafi AE. Fumaria parviflora-a review. Indo Am j pharm 2018; 5: 1728-38.

Almalki DA, Alghamdi SA. Hepatorenal protective effects of some plant extracts on experimental diabetes in male rats. Int J Pharmacol 2019; 15: 238-47. https://doi.org/ 10.3923/ijp.2019.238.247

Almeida DA, Braga CP, Novelli EL, Fernandes AA. Evaluation of lipid profile and oxidative stress in STZinduced rats treated with antioxidant vitamin. Braz Arch Biol Technol 2012; 55: 527-36. https://doi.org/10.1590/ S1516-89132012000400007

Alqasoumi SI, Al-Dosari MS, AISheikh AM, Abdel-Kader MS. Evaluation of the hepatoprotective effect of Fumaria parviflora and Momordica balsamina from Saudi folk medicine against experimentally induced liver injury in rats. Res J Med Plant 2009; 3: 9-15. https://doi.org/10.3923/rjmp.2009.9.15

Chaudhury D, Aggarwal A. Diabetic dyslipidemia: current concepts in pathophysiology and management. J Clin Diagn Res 2018; 12. https://doi.org/10.7860/JCDR/ 2018/29009.11090

Chidambara L, Singhal R, Srinivasan P, Yadav NK. Unreported side effect of intravitreal diclofenac in chronic diabetic macular edema. Retin Cases Brief Rep 2018; 12: 254-6. https://doi.org/10.1097/ICB.000000000 0000484

Classification and diagnosis of diabetes. American diabetic association 2017; 40: S11-S24. Availabla from: https://care.diabetesjournals.org/content/40/Supplement _1/S11. https://doi.org/10.2337/dc17-S005

Delkhosh A, Delashoub M, Tehrani AA, Bahrami AM, Niazi $\mathrm{V}$, Shoorei $\mathrm{H}$, et al. Upregulation of FSHR and PCNA by administration of coenzyme Q10 on cyclophosphamideinduced premature ovarian failure in a mouse model. $J$ Biochem Mol Toxic 2019; 33: e22398. https://doi.org/ 10.1002/jbt.22398

Fathiazad F, Hamedeyazdan S, Khosropanah MK, Khaki A. Hypoglycemic activity of Fumaria parviflora in streptozotocin-induced diabetic rats. Adv Pharm Bull 2013; 3: 207.

Fraser A, Harris R, Sattar N, Ebrahim S, Smith GD, Lawlor DA. Alanine aminotransferase, $\mathrm{Y}$-glutamyltransferase, and incident diabetes: the British Women's Heart and Health Study and meta-analysis. Diabetes care 2009; 32: 741-50. https://doi.org/10.2337/dc08-1870

Gamble JM, Donnan JR, Chibrikov E, Twells LK, Midodzi 
WK, Majumdar SR. The risk of fragility fractures in new users of dipeptidyl peptidase-4 inhibitors compared to sulfonylureas and other anti-diabetic drugs: A cohort study. Diabetes Res Clin 2018; 136: 159-67. https://doi.org/10.1016/j.diabres.2017.12.008

Guzzaloni G, Grugni G, Minocci A, Moro D, Morabito F. Liver steatosis in juvenile obesity: correlations with lipid profile, hepatic biochemical parameters and glycemic and insulinemic responses to an oral glucose tolerance test. Int J Obes 2000; 24: 772-6. https://doi.org/10.1038/ sj.ijo.0801224

Hasanpour M, Ashrafi M, Erjaee H, Nazifi S. The effect of saffron aqueous extract on oxidative stress parameters and important biochemical enzymes in the testis of streptozotocin-induced diabetic rats. Physiol Pharmacol 2018; 22: 28-37.

Hatting M, Tavares CD, Sharabi K, Rines AK, Puigserver P. Insulin regulation of gluconeogenesis. Ann Ny Acad Sci 2018; 1411: 21. https://doi.org/10.1111/nyas.13435

Ivanov I, Vrancheva R, Marchev A, Petkova N, Aneva I, Denev $\mathrm{P}$, et al. Antioxidant activities and phenolic compounds in Bulgarian Fumaria species. Int $\mathrm{J}$ Curr Microbiol App Sci 2014; 3: 296-306.

Kaleem M, Medha P, Ahmed QA, Asif M, Bano B. Beneficial effects of Annona squamosa extract in streptozotocin-induced diabetic rats. Singapore Med J 2008; 49: 800.

Kiafar E, Nasrabadi HT, Abedelahi A, Shoorei H, Seghinsara AM. Protective effects of vitamin $E$ and selenium on liver tissue damages induced by electromagnetic field: an ultrastructural study. Crescent J Med Biol Sci 2018; 5: 338-44.

Koye DN, Magliano DJ, Nelson RG, Pavkov ME. The global epidemiology of diabetes and kidney disease. Adv Chronic Kidney Dis 2018; 25: 121-32. https://doi.org/ 10.1053/j.ackd.2017.10.011

Kumar KN, Karunakar A, Gunesh G, Mukkanti K. Quantitation of protopine in Fumaria parviflora L. whole plant powder by high-performance liquid chromatography. Asian J Chem 2009; 21: 6695-700.

Lee $\mathrm{DH}$, Blomhoff R, Jacobs DR. Review is serum gamma glutamyltransferase a marker of oxidative stress? Free Radic Res 2004; 38: 535-9. https://doi.org/10.1080/ 10715760410001694026

Lenzen S. The mechanisms of alloxan- and streptozotocininduced diabetes. Diabetologia 2008; 51: 216-26. https://doi.org/10.1007/s00125-007-0886-7

Maritim A, Sanders a, Watkins lii JB. Diabetes, oxidative stress, and antioxidants: a review. J Biochem Mol Toxic 2003; 17: 24-38. https://doi.org/10.1002/jbt.10058

Osadebe PO, Odoh EU, Uzor PF. The search for new hypoglycemic agents from plants. Afr $\mathrm{J}$ Pharm Pharmaco 2014; 8: 292-303. https://doi.org/10.5897/ AJPP2014.3933

Paglia DE, Valentine WN. Studies on the quantitative and qualitative characterization of erythrocyte glutathione peroxidase. J Lab Clin Med 1967; 70: 158-69.

Pradeep K, Mohan CV, Gobianand K, Karthikeyan S. Silymarin modulates the oxidant-antioxidant imbalance during diethylnitrosamine induced oxidative stress in rats. Eur J Pharmacol 2007; 560: 110-6. https://doi.org/ 10.1016/j.ejphar.2006.12.023

Rauter AP, Martins A, Borges C, Mota-Filipe H, Pinto R, Sepodes B, et al. Antihyperglycaemic and protective effects of flavonoids on streptozotocin-induced diabetic rats. Phytother Res 2010; 24: S133-8. https://doi.org/ 10.1002/ptr.3017

Rawshani A, Rawshani A, Franzén S, Eliasson B, Svensson AM, Miftaraj $M$, et al. Mortality and cardiovascular disease in type 1 and type 2 diabetes. $\mathrm{N}$ Engl J Med 2017; 376: 1407-18. https://doi.org/10. 1056/NEJMoa1608664

Rizvi W, Naeem SS, Singh O, Akhtar K, Moin S, Kumar A. Hepatoprotective activity of fractions of Fumeria parviflora in anti tubercular drug induced toxicity in rats. Med Plant 2017; 3: 172-9. https://doi.org/10.5958/09756892.2017.00026.0

Roghani M. Fumaria parviflora Lam. effect on serum levels of glucose and lipids in streptozocin-induced diabetic rats. J Basic Clin Pathophysiol 2014; 2: 35-42.

Sauder KA, Stafford JM, Mayer-Davis EJ, Jensen ET, Saydah S, Mottl A, et al. Co-occurrence of early diabetes-related complications in adolescents and young adults with type 1 diabetes: an observational cohort study. Lancet Child Adolesc Health 2019; 3: 3543. https://doi.org/10.1016/S2352-4642(18)30309-2

Seghinsara AM, Shoorei H, Taheri MM, Khaki A, Shokoohi $M$, Tahmasebi M, et al. Panax ginseng extract improves follicular development after mouse preantral follicle 3D culture. Cell J (Yakhteh) 2019; 21: 210.

Shakya AK. Medicinal plants: future source of new drugs. Int J Herb Med 2016; 4: 59-64.

Shokoohi M, Khaki A, Shoorei H, Khaki AA, Moghimian M, Abtahi-Eivary $\mathrm{SH}$. Hesperidin attenuated apoptoticrelated genes in testicle of a male rat model of varicocoele. Androl 2020; 8: 249-58. https://doi.org/ 10.1111/andr.12681

Shokoohi M, Shoorei $H$, Soltani M, Abtahi-Eivari SH, Salimnejad R, Moghimian M. Protective effects of the hydroalcoholic extract of Fumaria parviflora on testicular injury induced by torsion/detorsion in adult rats. Androl 2018; 50: e13047. https://doi.org/10.1111/and.13047

Shokoohi M, Soltani M, Abtahi-Eivary SH, Niazi V, Poor MJ, Ravaei $\mathrm{H}$, et al. Effect of hydro--alcoholic extract of Olea europaea on apoptosis--related genes and oxidative stress in a rat model of torsion/detorsion-induced ovarian damage. Asian Pac J Reprod 2019; 8: 148. https://doi.org/10.4103/2305-0500.262831

Shoorei $H$, Khaki A, Khaki AA, Hemmati AA, Moghimian M, Shokoohi M. The ameliorative effect of carvacrol on oxidative stress and germ cell apoptosis in testicular tissue of adult diabetic rats. Biomed Pharmacother 2019; 111: 568-78. https://doi.org/10.1016/j.biopha. 2018.12.054

Shoorei H, Khaki A, Shokoohi M, Khaki AA, Alihemmati A, Moghimian $M$, et al. Evaluation of carvacrol on pituitary and sexual hormones and their receptors in the testicle of male diabetic rats. Hum Exp Toxicol 2020; 
0960327120909525. https://doi.org/10.1177/0960327 120909525

Srinivasan S, Yee SW, Giacomini KM. Pharmacogenetics of antidiabetic drugs. In: Advances in pharmacology. Elsevier, 2018, p.361-389. https://doi.org/10.1016/bs. apha.2018.04.005

Sun YI, Oberley LW, Li Y. A simple method for clinical assay of superoxide dismutase. Clin Chem 1988; 34: 497-500. https://doi.org/10.1093/clinchem/34.3.497

Tajik J, Nazifi S, Poorzal F. The effects of long-term use of Fumaria parviflora extract on some serum biochemical paranleters of rats. J Pharmacol Toxicol 2011; 6: 710-4. https://doi.org/10.3923/jpt.2011.710.714

Tripathi M, Singh BK, Mishra C, Raisuddin S, Kakkar P. Involvement of mitochondria mediated pathways in hepatoprotection conferred by Fumaria parviflora Lam. extract against nimesulide induced apoptosis in vitro. Toxicol In Vitro 2010; 24: 495-508. https://doi.org/10. 1016/j.tiv.2009.09.011

Van Wyk BE, Wink M. Medicinal plants of the world (CABI), 2018. https://doi.org/10.1079/9781786393258.0000 